\title{
Metabolite mobilization in the stem galls of Parthenium hysterophorus induced by Epiblema strenuana inferred from the signatures of isotopic carbon and nitrogen and concentrations of total non-structural carbohydrates
}

\author{
A. Raman $^{1, *}$, S. Madhavan², S.K. Florentine ${ }^{3,4}$ \& K. Dhileepan ${ }^{3,5}$ \\ ${ }^{1}$ The University of Sydney/Charles Sturt University, PO Box 883, Orange, New South Wales 2800, Australia, \\ ${ }^{2}$ Department of Biochemistry, The University of Nebraska, Lincoln, Nebraska 68588-0664, USA, ${ }^{3}$ Tropical Weeds Research \\ Centre, Queensland Department of Natural Resources and Mines, Charters Towers, Queensland 4820, Australia
}

Accepted: 30 November 2005

Key words: gall induction, source-sink relationships, carbon and nitrogen stable-isotopic measurements, assay, Lepidoptera, Tortricidae, Asteraceae, biological control, invasive weed

\begin{abstract}
Parthenium hysterophorus L. (Asteraceae) is a weed of national significance in Australia. Among the several arthropod agents introduced into Australia to control populations of P. hysterophorus biologically, Epiblema strenuana Walker (Lepidoptera: Tortricidae) is the most widespread and abundant agent. By intercepting the normal transport mechanisms of P. hysterophorus, the larvae of E. strenuana drain nutrients, other metabolic products, and energy, and place the host plant under intense metabolic stress. In this study, determinations of total non-structural carbohydrates (TNC) levels and carbon and nitrogen isotope ratios of fixed products in different parts of the plant tissue, including the gall, have been made to establish the function of gall as a sink for the nutrients.

Values of $\delta^{13} \mathrm{C}$ and $\delta^{15} \mathrm{~N}$ in galls were significantly different than those in proximal and distal stems, whereas the TNC levels were insignificant, when measured in the total population of P. hysterophorus, regardless of plant age. However, carbon, nitrogen, and TNC signatures presented significant results, when assayed in different developmental stages of $P$. hysterophorus. Carbon isotope ratios in galls were consistently more negative than those from the compared plant organs. Nitrogen isotope ratios in galls, on the contrary, were either similar to or less negative than the compared plant organs, especially within a single host-plant stage population (i.e., either rosette, preflowering, or flowering stage). TNC levels varied within compared plant populations. The stem distal to the gall functioned more efficiently as a nodal channel than the stem proximal to the gall, especially in the translocation of nitrogenous nutrients. Our findings indicate that the gall induced by E. strenuana functions as a sink for the assayed nutrients, although some variations have been observed in the patterns of nutrient mobilization. By creating a sink for the nutrients in the gall, E. strenuana is able to place the overall plant metabolism under stress, and this ability indicates E. strenuana has the necessary potential for use as a biological-control agent.
\end{abstract}

\author{
Introduction \\ Introduced accidentally from Central America in the 1950s, \\ Parthenium hysterophorus L. (Asteraceae) has emerged as a \\ *Correspondence: The University of Sydney/Charles Sturt University, \\ PO Box 883, Orange, New South Wales 2800, Australia. \\ E-mail: araman@csu.edu.au \\ ${ }^{4}$ Present address: School of Sciences and Engineering, University of \\ Ballarat, PO Box 663, Ballarat, Vic. 3353, Australia \\ ${ }^{5}$ Present address: Alan Fletcher Research Station, Department of Natural \\ Resources and Mines, PO Box 36, Sherwood, Qld 4075, Australia
}

weed of national significance in Australia (Navie et al., 1996). Because P. hysterophorus has been causing severe economic and environmental damage to the Australian crop and pasture industry (McFadyen, 1992; Chippendale \& Panetta, 1994) and also because various chemical and cultural methods have either proved uneconomic or ineffective (Holman \& Dale, 1981), measures of biological control are gaining validity in regulating its populations (McFadyen, 1992; Evans, 1997). Among the 10 insect species introduced between 1980 and 1999 from tropical America into Australia as possible agents to control P. hysterophorus 
(Florentine et al., 2001), the gall-moth Epiblema strenuana Walker (Lepidoptera: Tortricidae) has been found to have high potential in the management of $P$. hysterophorus populations (McFadyen, 1992; Dhileepan \& McFadyen, 2001). A majority of gall-inducing insects, especially their larval stages, are useful as efficient biological control agents of invasive weeds (Harris \& Shorthouse, 1996; Muniappan \& McFadyen, 2005). This is because the insect larvae (1) feed actively on growing plant parts, create a nutrient sink at the gall (Larson \& Whitham, 1991; Fay et al., 1993), and eventually weaken the overall metabolism of the host plant (Raman, 1993; Raman \& Abrahamson, 1995), and (2) remain highly specific to their host plants (Raman, 1996).

Parthenium hysterophorus is an annual herb with a deeply penetrating taproot system. It grows vigorously for about 16 weeks in the tropical and subtropical parts of Australia. When mature, its shoots grow up to $2 \mathrm{~m}$ in height and branch profusely. Young $P$. hysterophorus plants (3-4 weeks old) bear a rosette of leaves on condensed shoots, close to the soil surface. Flowering usually commences $6-8$ weeks after germination, and a fully grown plant produces ca. 25000 florets in its lifetime, with each inflorescence bearing four to five seeds (Dhileepan et al., 1996; Navie et al., 1996). Epiblema strenuana usually oviposit on tender leaves of P. hysterophorus. The neonate larvae gnaw the foliage briefly, and enter the stem by chewing the vegetative bud tissue and initiate galls, which include newly differentiated callus parenchyma functioning as nutritive cells. The larvae turn into pupae within fully developed galls $(2-3 \mathrm{~cm}$ long; $0.5-$ $1.0 \mathrm{~cm}$ wide at midpoint) and the pupal stage within the gall ranges from 4 to 6 days. At this stage of gall development, because of no feeding pressure, the nutritive cells become inactive, degenerate, and die. Adult moths emerge from the gall through a 'window' cut by the mature larva before pupation (Raman \& Dhileepan, 1999). Epiblema strenuana invades all stages of $P$. hysterophorus, however, the frequency of galls increases with the overall size of $P$. hysterophorus (Dhileepan, 2004).

By intercepting the normal transport mechanisms of P. hysterophorus, the larvae of E. strenuana drain nutrients, other metabolic products, and energy, and place the host plant under intense metabolic stress (Raman \& Dhileepan, 1999; Florentine et al., 2005; Miller, 2005). To determine the mobilization of carbon-based and nitrogenous nutrient compounds from plant parts other than the gall (source) of $P$. hysterophorus into the gall induced by E. strenuana (sink), we used stable-isotope ratio mass spectrometry, because this method is considered highly useful in interpreting the distribution and mobilization of nutrients in organic systems (see Rundel et al., 1989; Coleman \& Fry, 1991; Wada et al., 1998; Sagers et al., 2000). In this paper, we have tracked the mobilization of carbon-based and nitrogenous nutrients by following the signatures of carbon and nitrogen isotopes, as well as that of total nonstructural carbohydrates (TNC) with the questions: (1) Does carbon move from other parts of the plant (e.g., leaves, root) to the gall? (2) Does nitrogen move from other parts of the plant to the gall? (3) Do the results representing the movement of TNC (mobile sugars) synchronize with those of carbon movement? (4) Does the stem tissue proximal and distal to the gall play the role of an immediate source of carbon and nitrogen metabolites to the gall?

\section{Materials and methods}

\section{Sampling}

About 200 P. hysterophorus plants in rosette (3-4 weeks old), preflowering (6-8 weeks old), and flowering stages of development ( $\geq 8$ weeks old) were obtained randomly from private properties and crown land in Greenvale $\left(19^{\circ} 02^{\prime} \mathrm{S}\right.$, $\left.145^{\circ} 59^{\prime} \mathrm{E}\right)$, Charters Towers (20 $\left.55^{\prime} \mathrm{S}, 146^{\circ} 16^{\prime} \mathrm{E}\right)$, and Black Wattle Creek $\left(21^{\circ} 29^{\prime} \mathrm{S}, 146^{\circ} 40^{\prime} \mathrm{E}\right)$ in northern Queensland (Australia) during summer (December-March) and early autumn (April-May) of 2000. They were screened for galls induced by E. strenuana at the Tropical Weeds Research Institute's weed laboratory (Charters Towers, Queensland, Australia). Galled plants in the identified developmental stages [rosette stage $(n=20)$, preflowering stage $(n=30)$, flowering stage $(n=25)$ ] were segregated.

All the leaves (hereafter, leaves), galls, stem tissue $1 \mathrm{~cm}$ above the gall (hereafter, proximal stem), stem tissue $1 \mathrm{~cm}$ below the gall (hereafter, distal stem), and the entire root system (hereafter, roots) from every galled plant were separated. Individual galls from each plant were slit vertically to remove the inhabiting larva; frass that normally accumulates at one end of the gall was cleaned using a distilled-water jet. Subsamples of parts from each plant (i.e., leaves, galls, proximal stem, distal stem, and roots) were wrapped individually in dry aluminium foil and dried in an oven at $70{ }^{\circ} \mathrm{C}$ following Heberer et al. (1985), until the foil-wrapped plant parts reached a constant mass. Each subsample was hand-ground in an agate mortar $(300 \mathrm{ml}$ capacity), collected, and wrapped in dry aluminium foil, and stored at $35^{\circ} \mathrm{C}$ in an oven, until their transport to the Stable Isotope Laboratory (University of Nebraska, Lincoln, NE, USA). From the materials thus prepared 13 from the rosette, 22 from the preflowering, and 18 from the flowering stages were used randomly for Isotope Ratio Mass Spectrometry for $\delta^{13} \mathrm{C}$ and $\delta^{15} \mathrm{~N}$ measurements and TNC content determination: $65(13 \times 5)$ subsamples from the rosette, $110(22 \times 5)$ from the preflowering, and 90 $(18 \times 5)$ from the flowering stages were analysed for their carbon and nitrogen isotope ratios, and non-structural carbohydrate contents. 


\section{Determination of $\delta^{13} \mathrm{C}$ and $\delta^{15} \mathrm{~N}$ using isotope ratio mass spectrometry}

All the subsamples from the rosette (65), preflowering (110), and flowering stages (90) were fine-ground individually in liquid nitrogen in an agate mortar (50 ml capacity). Carbon isotope ratio measurements were made following Madhavan et al. (1991). For $\delta^{13} \mathrm{C}$ assays, plant materials from each of the above subsamples were weighed in a Sartorius $^{\mathrm{TM}}$ balance (sensitivity $\leq 0.01 \mathrm{mg}$ ) (Brinkmann Instruments, Inc., Westbury, NY, USA), ranging in mass between 2 and $4 \mathrm{mg}$, and for $\delta^{15} \mathrm{~N}$ assays, plant materials from each subsample were weighed, ranging in mass between 8 and $12 \mathrm{mg}$. Each of the weighed plant materials was individually packed in a boat-shaped tin container $(9 \times 5 \mathrm{~mm})$ (COSTECH Analytical Technologies, Inc., Valencia, CA, USA), with the edges tightly folded over it. These materials were analysed for their carbon and nitrogen isotope ratios using a Heraeus ${ }^{\mathrm{TM}}$ elemental analyser $(\mathrm{CHN}-$ O Rapid) (Elementar Analysensysteme GmbH, Hanau, Germany) interfaced with an automated trapping box system and Finnigan ${ }^{\mathrm{TM}}$ Delta-S isotope ratio mass spectrometer (Thermo Finnigan LLC, San Jose-Santa Clara, CA, USA). The isotope ratio of each sample was determined by comparison with a previously calibrated working standard (acetanilide) with a known $\delta^{13} \mathrm{C}$ value (precision $\pm 0.2 \%$ ) relative to PDB (Pee Dee Belemnite international standard) and a standard (nitroaniline) known $\delta^{15} \mathrm{~N}$ value calibrated against air standard.

The ${ }^{13} \mathrm{C}$ content of $\mathrm{CO}_{2}$ is given as an isotope ratio $[\mathrm{R}]$, where $\mathrm{R}=\left({ }^{13} \mathrm{CO}_{2}\right) /\left({ }^{12} \mathrm{CO}_{2}\right)$ and $\delta^{13} \mathrm{C}$ is given by $\delta^{13} \mathrm{C}=$ $1000\left[\left(\mathrm{R}_{\text {sample }} / \mathrm{R}_{\text {standard }}\right)-1\right]$. Isotope fractionation was related to $\delta^{13} \mathrm{C}$ values of the substrate $(\mathrm{S})$ and product $(\mathrm{P})$ by using the formula

$$
\Delta \delta=\frac{\delta^{13} \mathrm{C}_{\mathrm{S}}-\delta^{13} \mathrm{C}_{\mathrm{P}}}{1+\delta^{13} \mathrm{C}_{\mathrm{P}} / 1000}
$$

Because $1+\delta^{13} C_{\mathrm{p}} / 1000$ is usually of insignificant value, it was ignored and the calculations were made following $\Delta \delta=\delta^{13} \mathrm{C}_{\mathrm{S}}-\delta^{13} \mathrm{C}_{\mathrm{P}}$ (Madhavan et al., 1991).

Nitrogen isotope ratios were determined following the same set of equations described earlier for carbon isotope ratio determinations. As a general requirement, several runs of these respective standards and atmospheric air were made to calibrate the mass spectrometer and also to obtain standard data sets, before the combustion of subsamples of P. hysterophorus.

\section{Determination of total non-structural carbohydrate content}

Sample preparations were carried out following Swank et al. (1982). From the subsamples of $P$. hysterophorus materials used for $\delta^{13} \mathrm{C}$ and $\delta^{15} \mathrm{~N}$ evaluations, fine-ground tissue materials of known mass (80-100 mg) were weighed individually. They were placed in clean $100-\mathrm{ml}$ graduated cylinders and $25 \mathrm{ml}$ of $0.2 \mathrm{M}$ benzoic acid was added to each cylinder. The samples were autoclaved twice to hydrate the polysaccharides. After allowing the solution to cool, the volume of the solution was adjusted to $25 \mathrm{ml}$ with distilled water. An aliquot of $200 \mu \mathrm{l}$ from this solution was then removed and diluted to $750 \mu \mathrm{l}$ with $50 \mathrm{~mm}$ potassium acetate buffer ( $\mathrm{pH} 5$ ) and $0.02 \mathrm{~m}$ benzoic acid. This sample was then subjected to overnight hydrolysis, at $42{ }^{\circ} \mathrm{C}$, by treatment with $250 \mu \mathrm{l}$ of an amylase/amyloglucosidase solution. One millilitre sample from each incubated solution was then diluted with $1 \mathrm{ml}$ of distilled water. This solution was then assayed for TNC with the Nelson-Somogyi copper-reduction method (Spiro, 1966). Briefly, the tubes containing the samples were capped with glass marbles and placed in a boiling water bath for $10 \mathrm{~min}$. After cooling the tubes in a water bath maintained at room temperature, $1 \mathrm{ml}$ of arsenomolybdate was added to these solutions and stirred well. To each tube was then added $3 \mathrm{ml}$ of distilled water and absorbance measured at $600 \mathrm{~nm}$ in a Shimadzu UV-1601 ${ }^{\mathrm{TM}}$ spectrophotometer (Shimadzu Scientific Instruments, Columbia, MD, USA).

\section{Statistical analysis}

Data pertaining to carbon isotope ratios, nitrogen isotope ratios, and TNC content from the gall and non-gall tissues of $P$. hysterophorus were analysed using SIGMASTAT for Windows (version 2) (http://spssscience.co.kr/SigmaStat/) statistical software. We used two-way analysis of variance (general linear model analysis) to compare (i) between plant stages (i.e., rosette, preflowering, and flowering); (ii) between plant parts (e.g., leaves, proximal stem, gall, distal stem, and roots) from each of the plant stage; and (iii) the differences between plant stages and plant parts. To assess differences among organs within the same plant stage, we applied pairwise comparison (Tukey's test).

\section{Results}

Table 1 summarizes the results of the ANOVA performed for $\delta^{13} \mathrm{C}, \delta^{15} \mathrm{~N}$, and TNC signatures considering the total plant population (i.e., rosette + preflowering + flowering stages) assayed in this study. Evaluation of $\delta^{13} \mathrm{C}$ and $\delta^{15} \mathrm{~N}$ signatures in different plant stages, plant parts, and plant stages versus plant parts, under the galling impact of E. strenuana indicated significant differences, whereas that of TNC did not.

\section{Carbon isotope ratio $\left(\delta^{13} \mathrm{C}\right)$}

Pairwise multiple comparisons within the total population of $P$. hysterophorus indicated significant differences 
Table 1 Evaluation of signatures of carbon and nitrogen isotopes and total non-structural carbohydrates (TNC) in different plant stages and tissues (including galls and non-galled parts) from Parthenium hysterophorus infested by Epiblema strenuana

\begin{tabular}{|c|c|c|c|c|c|c|c|c|c|}
\hline \multirow[b]{2}{*}{ Source of variation } & \multicolumn{3}{|c|}{$\begin{array}{l}\text { Carbon isotope ratios } \\
{\left[\Delta\left(\delta^{13} C_{\text {air }}-\delta^{13} C_{\text {sample }}\right)\right]}\end{array}$} & \multicolumn{3}{|c|}{$\begin{array}{l}\text { Nitrogen isotope ratios } \\
{\left[\Delta\left(\delta^{15} \mathrm{~N}_{\text {air }}-\delta^{15} \mathrm{~N}_{\text {sample }}\right)\right]}\end{array}$} & \multicolumn{3}{|c|}{ TNC concentration } \\
\hline & d.f. & $\mathrm{F}$ & P-value & d.f. & $\mathrm{F}$ & $\mathrm{P}$-value & d.f. & $\mathrm{F}$ & P-value \\
\hline Plant stage & 2 & 94.040 & $<0.001$ & 2 & 11.107 & $<0.001$ & 2 & 2.217 & $\mathrm{~ns}^{1}$ \\
\hline Plant part & 4 & 114.597 & $<0.001$ & 4 & 205.597 & $<0.001$ & 4 & 0.277 & ns \\
\hline Plant stage vs. plant part & 8 & 8.067 & $<0.001$ & 8 & 39.287 & $<0.001$ & 8 & 0.308 & ns \\
\hline Residual & 119 & & & 55 & & & 70 & & \\
\hline
\end{tabular}

${ }^{1}$ ns - not significant.

between plant stage and plant part (Table 1). The relative content of carbon in different plant parts (e.g., leaves, gall, roots) differed among different plant stages $(\mathrm{P}<0.05)$ (Figure 1A-C).

Comparisons of values obtained from the gall and the remainder of plant parts differed significantly $(\mathrm{P}<0.05)$, whereas no difference occurred among the non-gall plant parts. Comparisons within the preflowering- and flowering- plant stages showed significant level of interaction among the compared plant parts, except the proximal stem and distal stem. All values obtained from 'between plant stages' on the factors of leaves, proximal stem, galls, distal stem, and roots were significant in their differences, except the gallvalue comparisons between flowering and preflowering stages, and roots-value comparisons between flowering and rosette stages (Figure $1 \mathrm{~A}-\mathrm{C}$ ).
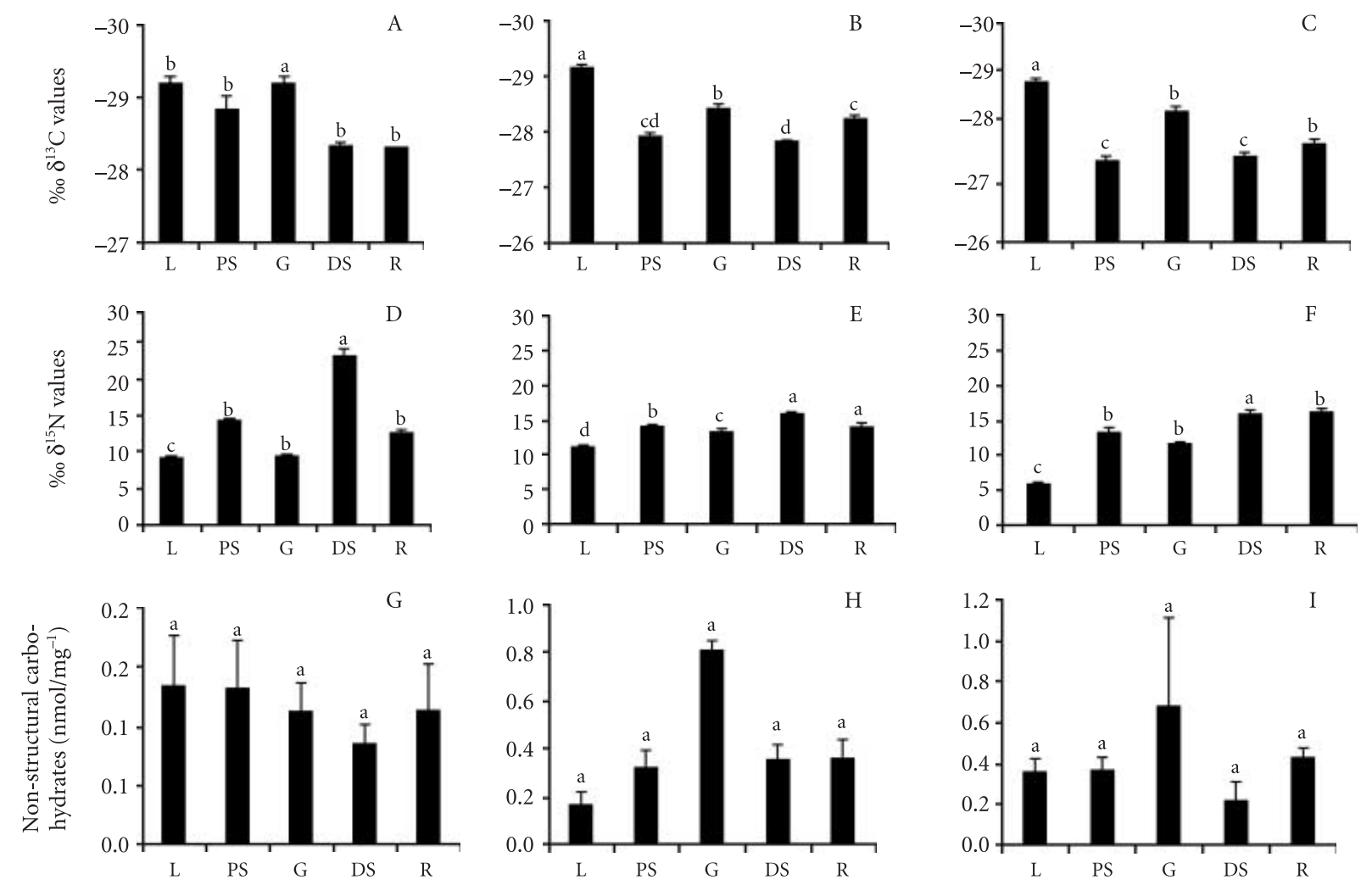

Figure 1 Mean values (+ SE of mean) of $\delta^{13} \mathrm{C}$ and $\delta^{15} \mathrm{~N}$, and levels of total non-structural carbohydrate (TNC) from the leaf (L), proximal stem (PS), gall (G), distal stem (DS), and root (R) from different developmental stages of Parthenium hysterophorus. Same letters indicate that means are not statistically different (Tukey's HSD test, $\mathrm{P}>0.05)$. (A-C) Carbon values $\left(\delta^{13} \mathrm{C}, \%\right.$ ) from rosette (A), preflowering (B), and flowering $(C)$ stages. (D-F) Nitrogen values $\left(\delta^{15} \mathrm{~N}, \%\right.$ o) from rosette (D), preflowering (E), and flowering (F) stages. (G-I) TNC levels from rosette $(\mathrm{G})$, preflowering $(\mathrm{H})$, and flowering $(\mathrm{I})$ stages. 


\section{Nitrogen isotope ratios $\left(\delta^{15} \mathrm{~N}\right)$}

Pairwise multiple comparisons within the total population of $P$. hysterophorus indicated significant difference between plant stage and plant part (Table 1). The relative isotope fractionation of nitrogen in different plant parts (e.g., leaves, gall, roots) differs among different plant stages $(\mathrm{P}<0.05)$ (Figure 1D-F).

Comparisons of the above-mentioned plant parts within the rosette-stage plants showed the values of leaves and roots significant different, whereas the values of distal stem (DS), gall (G), and roots (R) were not significantly different. Comparisons within the preflowering- and flowering-plant stages showed significant levels of interaction among the compared plant organs, except the values from roots and proximal stem in preflowering-plant stages, roots and galls in flowering-plant stages, and gall and proximal stem in both preflowering- and flowering-plant stages (Figure 1D-F).

\section{Total non-structural carbohydrates}

Total non-structural carbohydrate contents did not differ significantly among plant parts and plant stages (Table 1). Total non-structural carbohydrate values obtained from the comparisons of plant parts within individual plant systems as well as those comparing among the three growth stages of the host plant showed no significant trends either in the movement of TNC as such or in those carbohydrates moving in coordination with that of carbon from other plant parts to the galls (Figure 1G-I).

\section{Discussion}

Results obtained in this study demonstrate the mobilization of both carbon and nitrogen metabolites, as confirmed by stable isotope ratio mass spectrometry, in the stem galls of $P$. hysterophorus. Two-way analysis of the total plant population shows significant differences between plant stage and plant parts for carbon and nitrogen (Table 1). The relative content in different plant parts differs among plant stages (see also Figure 1). However, carbon, nitrogen, and TNC signatures assayed in the rosette-, preflowering-, and flowering-stage populations of $P$. hysterophorus presented contrasting, but significant readings. Carbon isotope ratios in galls were consistently more negative than those from the compared plant organs, viz., stem tissue proximal and distal to the gall and root, although the carbon values were significantly greater in the leaves than in the gall. Nitrogen isotope ratios in galls, on the contrary, were either similar to or less negative than the compared plant organs, especially within either rosette or preflowering or flowering stage population; $\mathrm{N}$ content in galls does not differ significantly from $\mathrm{N}$ content in proximal and distal stems in the rosette stage. Total non-structural carbohydrate signatures varied within compared plant populations, i.e., were lower in galls than other plant organs in rosette stages of $P$. hysterophorus $\left(0.0-0.2 \mathrm{nmol} \mathrm{mg}{ }^{-1}\right)$, and were higher in galls than other plant organs in the preflowering and flowering stages of P. hysterophorus $\left(0.0-1.2 \mathrm{nmol} \mathrm{mg}^{-1}\right)$. These results indicated that leaves, located above the E. strenuana-induced galls on the main stems of $P$. hysterophorus, are the principal source supplying carbon-based nutrients to galls, whereas the roots are the principal source supplying nitrogen-based nutrients. Total non-structural carbohydrate (mobile sugars) movement synchronizes with that of carbon especially during the preflowering stages (Figure $1 \mathrm{~B}, \mathrm{H}$ ) and flowering stages (Figure 1C,I); in terms of efficiency in performance, the distal stem functions more efficiently as a nodal channel than the proximal stem, especially in the translocation of nitrogen-based nutrients. In brief, nutrient concentrations within specific plant stages indicate that mobilization of carbon and TNC occurs in significant levels into galls from other plant parts in all developmental stages, whereas the mobilization of nitrogen to galls is modest from other plant parts, except roots.

In an earlier study (Florentine et al., 2005), we demonstrated that gall induction by E. strenuana on the stems of P. hysterophorus reduces the leaf-water potential, affects the photosynthetic rates negatively, and diminishes stomatal conductance, consequently reducing transpiration rates. Also, the energy levels in gall tissues and in stem-tissues distal to the galls were significantly greater than the energy levels in stem tissues proximal to the galls, irrespective of the developmental stage of host plants. Because the effects of gall induction on the incidence patterns of diverse minerals presented a varying picture, we proposed that the galls on P. hystrophorus induced by E. strenuana are 'mobilizing sinks' (sensu Craig et al., 1986).

In the present study, we have shown that the gall functions as a sink for carbon, similar to the results obtained in the leaf galls of Phanacis taraxaci (Hymenoptera: Cynipidae) on Taraxacum officinale (Bagatto et al., 1996). Lower nitrogen values in the galls of E. strenuana, compared with its values in other plant parts, indicate that E. strenuana regulates the mobilization of nitrogen-based nutrients, rather than concentrating them in the galls, similar to the observations of St John \& Shorthouse (2000) in the cynipid-induced galls on roses. Nonetheless, from the contrasting values of carbon and nitrogen in the galls of E. strenuana, we speculate that such a contrast is a consequence of down-regulation mechanism underlying photosynthetic acclimation (Campbell et al., 1988); in this instance, the down-regulation mechanism entails the allocation of less nitrogen in the carbon-enriched gall tissues of $P$. hysterophorus.

Although the values measuring the mobilization of non-structural carbohydrates nutrients and energy at gall 
sites indicate similar conclusions in both E. strenuana and $P$. taraxaci galls, the processes involved are different. Epiblema strenuana larvae induce single-chamber galls on the main stems of $P$. hysterophorus, by their biting and chewing action effected by the relatively large mandibulate mouthparts. Larvae of E. strenuana feed within the stem that includes the principal vascular cylinder of $P$. hysterophorus; they intercept and harness the carbon-based nutrients mostly from leaves and the nitrogen-based nutrients mostly from roots. Such a behaviour is similar to that of the tephritid Eurosta solidaginis, the inducer of ball galls on the stems of Solidago altissima (Asteraceae), which intercepts the photosynthates as they translocate along the main stem (Abrahamson \& Weis, 1997). By feeding on one side of the stem of $P$. hysterophorus, the larvae of E. strenuana damage and fracture parts of central-pith parenchyma and vascular strands [see Raman \& Dhileepan (1999) for vertical sections of the gall presenting an asymmetrical damage contour within the gall chamber]. Feeding action of gall-inducing cynipid larvae (e.g., Diplolepis spinosa and Diplolepis triforma) (St John \& Shorthouse, 2000), endowed with fine mouthparts and in consequence, they neither fracture vascular strands nor disturb the flow of sap and nutrients. In fact, the larval stages of several gall-inducing aphids and gall midges that feed on their host-plant tissues inflicting 'fine' to 'microfine' injury are capable of either inducing the generation of a sophisticated vascular network pattern unknown in the normal plant organs (Wool et al., 1999) or eliciting specialized non-vascular transport mechanisms (Rohfritsch, 1988) in their galls. In contrast, the E. strenuana larvae fracture the conducting parenchyma and vascular elements and their feeding damage induces hypertrophy of vascular parenchyma and phloem elements (Raman \& Dhileepan, 1999). Nonetheless, the feeding action of E. strenuana larvae triggers the regeneration of callus cells from the damaged vascular parenchyma; such regenerated callus parenchyma and the intact vascular tissues from the unfed side within galls facilitate the horizontal and vertical mobilization of metabolites. Therefore, the continuous feeding pressure imposed by E. strenuana larva accelerates mobilization of nutrients at the gall.

Our findings indicate that the gall induced by E. strenuana functions as a sink for carbon-based and nitrogenous nutrients, although some variations in the patterns of nutrient mobilization were evident. By creating a sink for the nutrients in the gall, E. strenuana is able to place the overall host-plant metabolism under stress, a trait necessary for an effective biological control agent.

\section{Acknowledgements}

We thank Dr Cameron Hurst (School of Information Technology and Mathematical Sciences, The University of
Ballarat, Ballarat, Victoria, Australia) for advice on statistical procedures. AR thanks the Ian Potter Foundation (Melbourne, Australia) and the University of Sydney (Sydney and Orange campuses, Australia) for supporting his travel to the University of Nebraska, Lincoln, NE, USA. An R and D grant (no. NRM/185/001:1221:BV:IT) from the Queensland Department of Natural Resources and Mines supported this study.

\section{References}

Abrahamson WG \& Weis AE (1997) Evolutionary Ecology Across Three Trophic Levels: Goldenrods, Gallmakers, and Natural Enemies. Princeton University Press, Princeton, NJ.

Bagatto G, Paquette LC \& Shorthouse JD (1996) Influence of galls of Phanacis taraxaci on carbon partitioning within common dandelion, Taraxacum officinale. Entomologia Experimentalis et Applicata 79: 111-117.

Campbell WJ, Allen LH \& Bowes G (1988) Effects of $\mathrm{CO}_{2}$ concentration on rubisco activity, amount and photosynthesis in soybean leaves. Plant Physiology 88: 1310-1316.

Chippendale JF \& Panetta FD (1994) The cost of Parthenium weed to the Queensland cattle industry. Plant Protection Quarterly 9: 73-76.

Coleman DC \& Fry B (1991) Carbon Isotope Techniques. Academic Press, New York, NY, USA.

Craig TP, Price PW \& Itami JK (1986) Resource regulation by a stem-galling sawfly on the arroyo willow. Ecology 67: 419425.

Dhileepan K (2004) The applicability of plant vigor and resource regulation hypotheses in explaining Epiblema gall mothParthenium weed interactions. Entomologia Experimentalis et Applicata 113: 63-70.

Dhileepan K, Madigan B, Vitelli M, McFadyen R, Webster K \& Treviño M (1996) A new initiative in the biological control of parthenium. Proceedings of the First International Conference on Parthenium Management (ed. by M Mahadeveppa \& VC Patil), pp. 40-44. The University of Agricultural Sciences, Dharwad, India.

Dhileepan K \& McFadyen R (2001) Effects of gall damage by the introduced bioconrol agent Epiblema strenuana (Lep., Tortricidae) on the weed Parthenium hysterophorus (Asteraceae). Journal of Applied Entomology 125: 1-8.

Evans HC (1997) Parthenium hysterophorus: a review of its weed status and the possibilities of biological control. Biocontrol News and Information 18: 39N-98N.

Fay PA, Hartnett DC \& Knapp DC (1993) Increased photosynthesis and water potential in Silphium integrifolium galled by cynipid wasps. Oecologia 93: 114-120.

Florentine SK, Raman A \& Dhileepan K (2001) Gall-inducing insects and biological control of Parthenium hysterophorus L. (Asteraceae). Plant Protection Quarterly 16: 1-7.

Florentine SK, Raman A \& Dhileepan K (2005) Effects of gall induction by Epiblema strenuana on gas exchange, nutrients, and energetics in Parthenium hysterophorus. BioControl 50: 787-801. 
Harris P \& Shorthouse JD (1996) Effectiveness of gall inducers in weed biological control. The Canadian Entomologist 128: 1021-1055.

Heberer JA, Below FE \& Hageman RH (1985) Drying methods effect on leaf chemical constituents of four crop species. Crop Science 25: 1117-1119.

Holman DJ \& Dale IJ (1981) Parthenium weed threatens Bowen Shire. Queensland Agricultural Journal 107: 57-60.

Larson KC \& Whitham TG (1991) Manipulation of food resources by a gall-forming aphid. The physiology of sourcessink interactions. Oecologia 88: 15-21.

Madhavan S, Treichel I \& O'Leary MH (1991) Effects of relative humidity on carbon isotope fractionation in plants. Botanica Acta 104: 292-294.

McFadyen RE (1992) Biological control against parthenium weed in Australia. Crop Protection 11: 76-88.

Miller WE (2005) Gall-inducing Lepidoptera. Biology, Ecology, and Evolution of Gall-Inducing Arthropods (ed. by A Raman, CW Schaefer \& TM Withers), pp. 429-462. Science Publishers, Inc, Enfield, NH, USA.

Muniappan R \& McFadyen RE (2005) Gall-inducing arthropods used in the biological control of weeds. Biology, Ecology, and Evolution of Gall-Inducing Arthropods (ed. by A Raman, CW Schaefer \& TM Withers), pp. 705-726. Science Publishers, Inc, Enfield, NH, USA.

Navie SC, McFadyen RE, Panetta FD \& Adkins SW (1996) The biology of the Australian Weeds, 27. Parthenium hysterophorus. Plant Protection Quarterly 11: 400-407.

Raman A (1993) Chemical ecology of gall insect-host plant interactions: substances that influence the nutrition and resistance of insects and the growth of galls. Chemical Ecology of Phytophagous Insects (ed. by TN Ananthakrishnan \& A Raman), pp. 227-250. Oxford \& IBH Publishing Co, New Delhi, India.

Raman A (1996) Nutritional diversity in gall-inducing insects and their evolutionary relationships with flowering plants.
International Journal of Ecology and Environmental Sciences 22: $150-160$.

Raman A \& Abrahamson WG (1995) Morphometric relationships and energy allocation in the apical rosette galls of Solidago altissima (Asteraceae) induced by Rhopalomyia solidaginis (Diptera: Cecidomyiidae). Environmental Entomology 24: 635-640.

Raman A \& Dhileepan K (1999) Qualitative evaluation of damage by Epiblema strenuana (Lepidoptera: Tortricidae) to the weed Parthenium hysterophorus (Asteraceae). Annals of the Entomological Society of America 92: 717-723.

Rohfritsch O (1988) Food supply mechanism related to gall structure with the example of Geocrypta galii Lw., (Cecidomyiinae, Oligotrophini) on Galium mollugo. Phytophaga 2: 1-17.

Rundel PW, Ehleringer JR \& Nagy KA (1989) Stable Isotopes in Ecological Research. Springer-Verlag, Berlin, Germany.

Sagers CL, Ginger SM \& Evans RD (2000) Carbon and nitrogen isotopes trace nutrient exchange in an ant-plant mutualism. Oecologia 123: 582-586.

Spiro RG (1966) Analysis of sugars found in glycoproteins. Methods in Enzymology 8: 3-26.

St John MG \& Shorthouse JD (2000) Allocation patterns of organic nitrogen and mineral nutrients within stem galls of Diplolepis spinosa and Diplolepis triforma (Hymenoptera: Cunipidae) on wild roses (Rosaceae). The Canadian Entomologist 132: 635-648.

Swank JC, Below FE, Lambert RJ \& Hageman RH (1982) Interaction of carbon and nitrogen metabolism in the productivity of maize. Plant Physiology 70: 1185-1190.

Wada E, Tayasu I, Kora K, Matsubara T, Ogawa NO et al. (1998) The use of stable isotopes in ecological studies. Ecology Today: An Anthology of Contemporary Ecological Research (ed. by B Gopal, PS Pathak \& KG Saxena), pp. 407-430. International Scientific Publications, New Delhi, India.

Wool D, Aloni R, Ben-Zvi O \& Wollberg M (1999) A galling aphid furnishes its home with a built-in pipeline to the host food supply. Entomologia Experimentalis et Applicata 91: 183-186. 